\title{
Gтарннная музыка
}

\section{Маргарита Григорьева}

\section{РАННЕПЕЧАТНЫЕ ИЗДАНИЯ СОЧИНЕНИЙ ДЖЕЗУАЛЬДО}

Обзор прижизненных изданий нот Карло Джезуальдо приоткрывает некоторые страниџы его жизни и творчества. Рисунки на титулах его нот ярко передают характе эпохи Ренессанса с типичной для нее атрибутикой и, вместе с тем, выявляют и нечто особенное, говорящее о мире самого композитора.

Перед нами титульный лист Первой книги мадригалов в феррарском издании 1594 года:

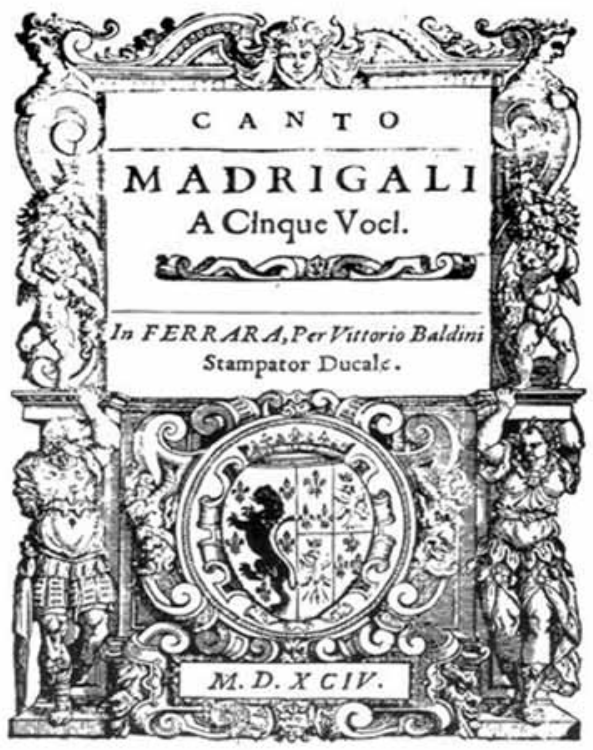

Libro Primo dei Madrigali. Froetespixio
Джезуальдо прибыл в Феррару в феврале 1594 г. по приглашению герцога Альфонсо II д'Эсте для женитьбы на его двоюродной сестре Элеоноре д’Эсте. Это был для Джезуальдо второй брак, через 4 года после трагически закончившегося первого. Среди прочего багажа он вез с собой два сборника мадригалов, о чем мы узнаем из письма, посланного герџогу придворным композитором Альфонсо ФОотанелли из Ардженто, небольшого городка, где обоз остановился накануне въезда в Феррару [4]. Среди прочего, ФОонтанелли пишет: «Porta seco due mute di libri a cinque voci» (везет с собой два комплекта книг на 5 голосов) [4, с. 414]. Эти мадригалы были подписаны чужим именем Джузеппе Пилоний, о чем мы узнаем несколько позже из предисловия Шипьоне Стеллы (музыканта, приехавшего с князем в Феррару) ко 2-й книге Мадригалов Джезуальдо: «data in luce (т.е. вышедшие в свет, или - увидевшие свет) sotto il nome di Giuseppe Pilonij». Объяснение такого типа издания лежит в тогдашних представлениях о соџиальном положении князя, сочинение музыки для которого считалось «черным» трудом, таким же, как и любой другой труд. Князь сочинял музыку как любитель, diletto, 
каковыми были тогда многие аристократы. Это название, увы, надолго закрепи лось за Джезуальдо. Сам же Джезуальдо, видимо, высоко џенил свои сочинения, они, напомню, были у него в двух әкземплярах - один для практического употребления (т.е. исполнения), а другой для демонстраџии своей композиторской техники, дабы смотрящие могли восхишаться его искусством: « Ne fa apertissima professione et a merviglia [изумляться, поражаться] dell' arte sua» [4, с. 413]. Видимо, он вез эти книги в Феррару, рассчитывая там на их издание и, может быть, вовсе не случайно показал их Фонтанелли в Ардженто. Действительно, они были изданы в Ферраре в мае и июне этого же года, одна за другой (правда, в перепутанном порядке), всего через несколько месяцев после приезда.

Что же мы видим на титульном листе этого издания? Фреррара в конџе XVI века была городом, богатым не только политически и экономически, но и в интересуюшем нас культурном смысле, конкретно - в музыкальном отношении. Герџог Альфонсо II д'Эсте был покрови телем искусства. При своем дворе он содержал капеллу, maestro di capella был синьор Фьорино (Fiorino). Там же работал органист и композитор Ауџџаско Луџџаски, умевший, среди прочего, играть на удивительном инструменте - архиклавесине, сконструированном Николо Вичентино, а в прежние годы, при других д'Эсте, работали выдающиеся музыканты - Якоб Обрехт, Жоскен Депре, Чиприано де Роре (их там называли oltramontani, т.е прибывшими из-за гор), приезжавшие учиться у итальян- џев и обогащавшие их искусство своими достижениями. Постоянно устраивались музыкальные вечера для себя и для именитых гостей. Истинной жемчужиной этих конџертов был знаменитый ансамбль Concerto delle dame. Сначала певиџы были из благородных дам, но по мере их успеха, когда многие композиторы стали спејиально писать для них все более сложные произведения (наполненные многочисленными украшениями, длинными пассажами, требовавши ми искусного владения голосом, при этом с инструментальным сопровождением самих же участниџ на виолах, арфе, лютне), появилась необходимость в профессиональных исполнительнијах. На эти «тайные» вечера допускалось малое число высокопоставленных гостей - правители, послы, придворные, поэты, иностран ные артисты, - которые наслаждались ангельскими голосами. Художественные достижения этого ансамбля подняли престиж двора Альфонсо, амбиџиозно настроенные семьи последовали их примеру. Сочинения делались таким образом, чтобы показать особо изощренное искусство певиџ - и соло, и в ансамбле. Все это требовало огромной работы, в том числе, издания все новых и новых нот. При дворе д'Эсте было свое издательство (нотопечатня) во главе с Витторио Бальдини, по-видимому, замечательным спеџиалистом, как о том пишет А. Ваккаро [7] Ферраре повезло с издателем.

Титульный лист мадригалов Джезуальдо характеризует, скорее всего, не столько композитора, сколько «бренд» феррарского издательства. Он пышно декорирован растительным орнаментом, 
листьями, џветами, плодами (лотос, папирус, пальметта, акант, использовавшиеся как знак триумфа и преодоления жизненных испытаний). Это был типичный для того времени стиль, он в то же время свидетельствовал о богатстве и благополучии герџогства.

В џентре, под названием сборника овал, в котором мы видим два совмешенных герба - семейства Джезуальдо и семейства д'Эсте. Герб Джезуальдо представляет собой стояшего на задних лапах черного льва, окруженного пятью красными лилиями. Торквато Тассо в диалоге Граф, или о Деяниях (Il Conte ovvero delle Imprese) в высоком (хвалебном) стиле представляет происхождение семьи, видя в этой символике благородство древних норманских князей, короля Гульельмо, его родителей или предков. B Gerusalemme Conquistata (Завоеванный Иерусалим), в стансах 132 и 133 он пишет об этом же стихами:

Due regIe stirpi, e gloriose, e chiare,

In cui riluce lo splendor vetusto

E Carlo, a cui par che Venosa adorni

Armi, e corone, e la famosa cetra

[Потомки двух королевских домов, и славных, и знаменитых,

В которых отражается свет старинного величия:

И Карло, для которого, кажется, Веноза украшается

Оружием, и коронами, и знаменитым шитом (или џитрой)]

Лилии на знаменах или гербах - от французских королей (считается, что семейство Джезуальдо прибыло в Италию из Франџии). В џентре титульного листа информаџия о сборнике и его издании: Madrigali a cinque voci, под ним место издания - in Ferrara, имя печатника Vittorio Baldini, stampatore ducale (герџогским печатником), и год издания римскими џифрами MDXCIV. Верхняя надпись Canto указывает, что это партия («книга») для верхнего голоса. (Напомним, что именно так, «книгами» для каждого голоса, издавались ноты; в частности, в результате потери двух книг, bassus и sextus, Второй сборник Священных песнопений [Sacrae cantiones] сушествует в неполном виде и непригоден для исполнения, кроме тех трех, к которым дописал недостающие партии И.Ф. Стравинский). Заметим, что имя автора (ни настоящее, ни псевдоним) здесь вовсе не указано. И это тоже определенным образом характери зует время и место издания.

Иную картину представляют титульные листы Пятой и Шестой книг мадригалов. Они были изданы в 1611 году в городе Джезуальдо. Годы, разделявшие эти два издания, были непростыми в жизни композитора. С одной стороны, он стремился в Феррару, где все привлекало Джезуальдо-музыканта. Вместе с тем, первые же годы жизни в Ферраре наметили и в дальнейшем усугубили конфронтаџию князя Венозы и двора. Композитору хотелось безусловного признания, причем не только в Ферраре, но и в других местах, двору же казались непомерными его притя зания («affetto napuletanissimo», с иронией говорили о нем). После ряда отъездов (первый из которых состоялся буквально через три месяџа) и возврашений, Джезуальдо в 1596 г. уезжает из 
Феррары и, после нескольких попыток воссоединения с семьей, окончательно покидает город. Местом дальнейшего пребывания оказывается по большей части родовой замок (il castello) в Джезуальдо, который он приспособил как можно лучше для жизни, богато украсив его. Судя по описи имущества в 1607 году [5, c. 124-127], там было множество драгоценностей - диаманты, изумруды, жемчуг, рубины, золото, оружие, музыкальные инструменты. Возможно, он создал собственную капеллу (так как некоторые музыканты, уехавшие с ним в свое время в Феррару, вернулись) и, что важно для нас, устроил там типографию. Издателем был Джованни Джакомо Карлино (Giovanni Giacomo Carlino), знаменитый печатник из Неаполя, приглашенный композитором в свое имение на два года. Так амбиџиозный князь хотел сравниться с двумя лучшими в ту пору издательствами - Бальдини в Ферраре и Гардано в Венеции.

Титульные листы Пятой и Шестой книг выглядят по сравнению с феррарски ми скромнее:

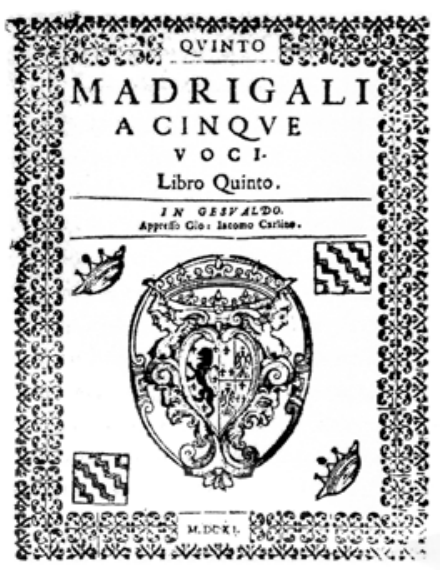

По краям вместо затейливого густого орнамента - однотипный рисунок, в џентре - тот же герб, но на свободном пространстве в верхнем левом и нижнем правом углу изображены короны. Возможно, они должны были символизировать ощущение некоего господства, власти. С таким самоощушением корреспондирует и Предисловие издателя, обращенное к композитору:

Моему прославленнейшему, превосходнейшему господину Карло Джезуальдо, графу Кониьи, князю Венозы, и проч., и проч. Государь мой и премногоуважаемый покровитель.

Смиренное и скромное желание как можно долее уберечь Ваши редкие музыкальные сочинения от восторгов публики, свойственное Вашему Превосходительству от природы, нашло сильного противника в лище великого их искусства и изяществв. Стоило появиться творению на свет, как ему выпала судьба услаждать своими красотами лишь узкий домашний круг, без надежды на печатный станок, мысль о котором столь враждебна вкусу Вашего Превосходительства. Но это повело не только к тому, что некоторые, подчиняясь искреннему желанию насладиться столь превосходными сочинениями, разньми тонкими ухищрениями добывали даже и неаккуратные списки, но и к тому, что некие композиторы, пользуясь случаем, возжелали восполнить скудость собственного таланта мошенническим образом, припи сав себе многие прекрасные пассажи из сочинений и многие новшества, введен- 
ные Вашим Превосходительством, как это и случилось с настоящии, пятым томом Ваших чудесных мадригалов. Посему после того, как свет нетерпеливо ждал в продолжение пятнадиати лет со времени их создания, я же ожидая десять лет, должным образом исполняя Ваше приказание, тем самым приложил все усилия, дабы они не покинули домашнего круга. Увидев, что заботы мои пропали втуне, и будучи исполнен сочувствия при виде того, как редчайшие сочинения ходят по рукам в столь извращценном виде, словно бесиенные камни, оправленные в свинеи, решился я по достоинству услужить Вашей Светлости, проявить милосердие и справедливость, прибегнув к печатному станку в надежде, что Ваше Превосходительство, выбирая меньшее из двух зол, одобрит мое рвение и не посмотрит с пренебрежением на пыл своего верного, хоть и нижайтего, слуги. Дабы Вы милостиво соизволили извинить мне упущесния, буде таковые отьциутся, и таким образом по-новому взглянув на Ваши работь, освобожденные от самозваных подделок, Вам посвящлаю я это печатное издание и склоняюсь пред Вами в глубочайшем почтении. В Джезуальдо, двадиатого июня, 1611.

Смиренно и преданно,

Don Gio: Pietro Cappuccio [7, c. 155-156].

Стиль этого предисловия не может нас обмануть, оно написано, скорее всего, самим композитором, уже вполне осознавшим свое значение, изображение королевских корон которому впол- не соответствует. Вместе с тем, это издание - настоящий завет композитора, его послание через века. Ныне музыка Джезуальдо звучит в разных странах, количество ансамблей, ее исполняющих, все увеличивается. Назовем хотя бы некоторые из них: Métamorphose, Collegium Vocale, Hilliard-ensemble, Oxford Camerata, Quintetto-vocale, Musica ficta, A sei voci, Delitiæ Musicæ (под управлением Marco Longhini).

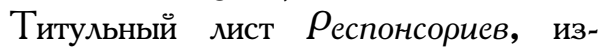
данных там же и тогда же, имеет сходный с мадригалами абрис, та же вертикальная композиџия с гербом в центре, с табличной надписью, с фигурами по бокам:

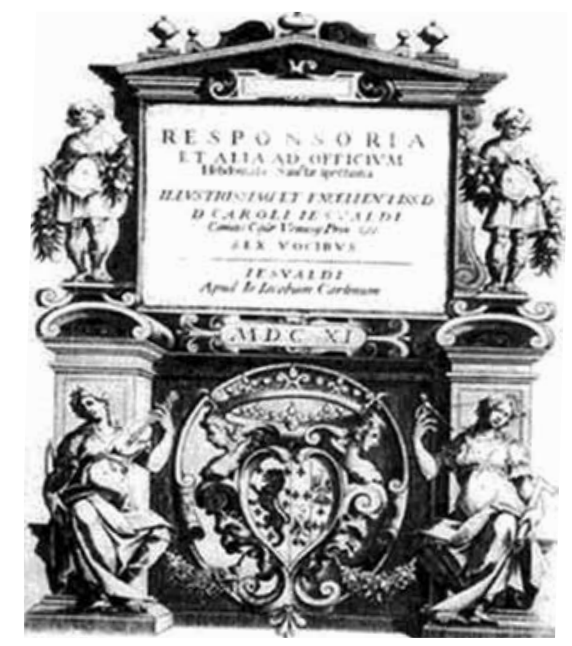

Здесь мы видим и название на латинском языке: Responsoria et alia ad officium (Респонсории и другие [песнопения] для Страстной недели), и, что важно, имя композитора и его регалии: illustrissimi et exellentiss. D. Caroli Iesualdi (сиятельнейший [знаменитый, знатный] и превосходнейший дон Карло Джезуальдо), граф 
Конџы, князь Венозы и т.д. И ниже еше раз Iesualdi, указываюшее на место издания, имя издателя apud Jacobum Carlinum (у Джакомо Карлино), и год издания MDCXI (1611).

Служба Заутрени на Страстной неделе - одна из наиболее драматических из полного џерковного года. Она включает три собрания (Великий Четверг, Великая Пятниџа и Великая Суббота), каждое из девяти частей. Кроме того, в сборник входит известный покаянный псалом Miserere и Песнь Захарии Benedictus.

Респонсории как жанр духовной музыки в определенной степени характеризуют духовный мир композитора. Он не написал ни одной мессы, каковые писали композиторы эпохи Возрождения, а вместо канонического текста мог выбирать его по своему усмотрению. Тексты Респонсориев заимствованы им из Псалтири и других библейских книг, но их выбор говорит о стремлении композитора воплотить образы страдания.

Я сравнялся с нисходящиими в могилу, я стал, как человек, беспомощный, между мертвыми боошенный.

$$
* * *
$$

Положили меня в ров преисподний, во мрак и тень смертную.

$$
* * *
$$

О все вы, проходящие путем,

внемлите и смотрите, есть ли боль, как моя боль?

(и т.д.).

В таких текстах отражается следование принџипам иезуитов (с которыми было связано семейство Джезуальдо): художник, изображая страсти, должен в полной мере ощушать их ужас, слезы, скорбь и угрызения совести. «Представить, что мы сами осязаем этот огонь, как он прикасается к душам и сожигает их» (Игнатий Лойола, Духовные упражнения). Обрашение к Богу, показательное для эпохи в целом, у Джезуальдо имело особое значение. По материнской линии он происходил из рода высшего духовенства. Брат матери, Карло Борромео, был кардиналом и архиепископом Милана, впоследствии - в 1610 г., еше при жизни композитора - был канонизирован (он изображен на алтарной картине Il perdono). Другой дядя, из семейства князей Джезуальдо, Альфонсо Джезуальдо, был архиепископом Неаполя. Будучи вторым сыном, Карло по традиџии готовился к духовной карьере, и лишь преждевременная смерть старшего брата автоматически сделала его князем Венозы. Кроме того, к мыслям о Боге его, видимо, постоянно привлекала личная трагедия. Как известно, в 1590 году он на почве ревности убил свою первую жену, Марию д’Авалос, и ее любовника, СОабриџио Караффу, после чего укрылся на несколько лет в родовом замке. Вся последуюшая жизнь осложнялась расстроенной психикой, приводившей нередко к патологическим проявлениям. В поисках прошения композитор выстроил несколько џерквей, в том числе в городе Джезуальдо церковь капуџинов Santa Maria delle Grazie, а в 1609 году разместил в ней картину Il perdono, на которой живописными средствами выражена мольба к Богу о прощении [См.: 1]. 
Но музыка респонсориев никак не свидетельствует о смирении - это тот же язык, что и в последних книгах мадригалов. Музыкальный язык поздних сочинений един. Если бы Джезуальдо мыслил церковную музыку стилистически иначе, он мог бы использовать хотя бы мелодические формулы хорала. Но их нет, музыка Респонсориев наполнена сложными сочетаниями, хроматизмами, яркими контрастами, диссонансами, точно так же, как и мадригалы Пятой и Шестой книг. Так что метафорически можно сказать, что Респонсории - те же мадригалы на библейские тексты: если слушать эту музыку без слов, или без перевода, можно принять их за мадригалы. Это «противоречие» нашло отражение и в оформлении нот.

Ориентируясь на содержание текстов Респонсориев, Гленн Уоткинс в книге «The Gesualdo Hex» [8] видит на их титульном листе знаки обращения к Богу. В левой фигуре - соответствие текста, направленного к Богу, и выражающей его музыки, в правой - инструменты архитекторов, которые автор ассоџиирует с максимой: Бог - архитектор вселенной.

На самом деле здесь нет ни одного христианского атрибута, напротив, античные, точнее, псевдоантичные (языческие) символы. Наверху юноши, либо нимфы, спутниџы Артемиды, в руках их ветви и плоды знаки плодородия. К гербу примыкают чудища, типа Диониса / Вакха (они же, вспомним, и на титульных листах первых книг мадригалов). Они сродни созданным примерно в ту же эпоху знаменитым маньеристским портретам стихий мироздания Арчимбольдо, которые сделаны из плодов, растений, рыб и т.п. Нижние же женские фигуры - музы, но не в античном, а, скорее, в средневековом смысле - соответствуют Музыке и Арифметике. Музыку мы опознаем по инструменту в левой руке (виола?) и смычку в правой. Она склонилась над книгой, это символ союза музыки и слова. У правой фигуры в руках џиркуль и наугольник, измерительные приборы. Вместе с тем, еще в средневековых рукописях и раннепечатных книгах Музыку начали изображать как символ чувства, а Арифметику как символ разума. Таким образом, изображение двух квадривиальных наук здесь можно истолковать как союз sensus и ratio, что, в свою очередь, свидетельствует об антикизаџии в культуре Ренессанса: связь с традиџией античности никогда не прерывалась. «Музы» в ренессансном стиле (типичная метаморфоза!) выглядят вполне реалистично - пышнотелыми, земными. Одеяния их, весьма вольные - прозрачные накидки, сквозь которые просвечивает тело, - подчеркивают их земную, плотскую сущность.

Здание, которое Уоткинс трактует как намек на церковь Santa Maria delle Grazie, с размешенной в ней картиной Il perdono как символ покаяния (по мысли автора, там композитор как бы предполагал исполнение респонсориев). Однако, на самом деле оно мало похоже на џерковь. Это, скорее, богатое светское здание, может быть, некий условный театр, наполненный удивительными персонажами. За гербом угадывается нечто похожее на занавес, как бы еще закрытый. Вход в него загораживают чудиша с торчашими из их ртов ветвями. За этим скрыт таинственный и сложный мир человеческих страстей, что укрепляет нас в теоретической гипотезе, что с точки 
зрения эстетики и стиля, несмотря на колоссальное различие текстов, и мадригалы, и духовные сочинения представляют собой у Джезуальдо единое целое.

Таким образом, перед нами удивительный феномен, новое слышание и видение, свойственное Ренессансу в его завершающей стадии - маньеризме.

Последуюшие издания нот Джезуальдо выполнены более формально:

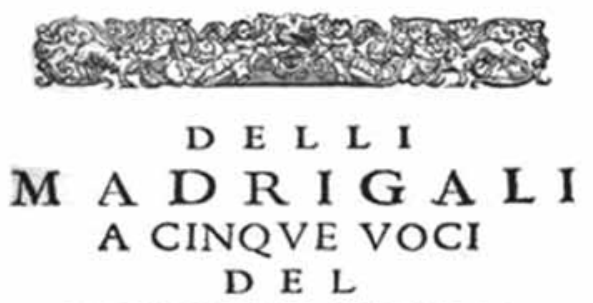

PRENCIPE DI VENOSA HBRO शVINTO.

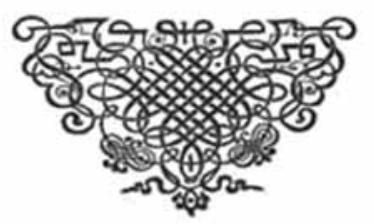

Это титульный лист Пятой книги из издания всех шести книг мадригалов генуэзца Симоне Молинаро, увидевшее свет в 1613 году, в год смерти Джезуальдо. Не сохранилось никаких свидетельств, видел ли это издание композито , а ведь оно было принџипиально иным: во-первых в виде партитуры, и во-вторых - с расставленными тактовыми чертами, чего не было в прижизненных изданиях поголосников:
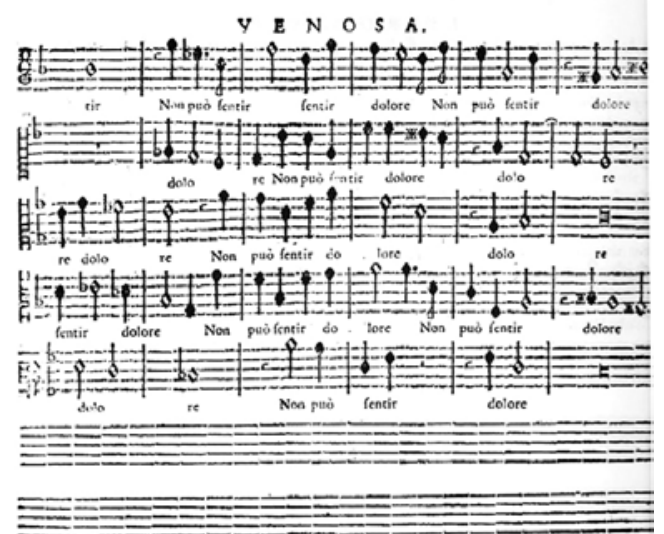

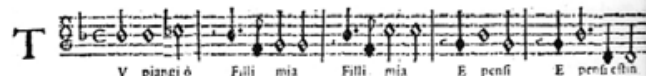

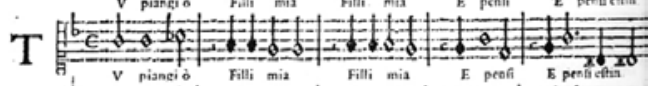

$T$ 后它-

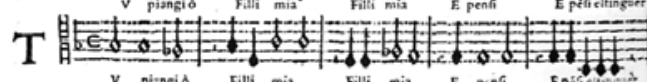

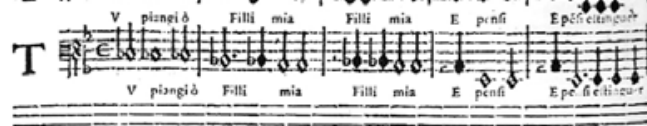

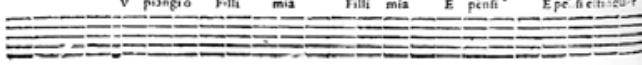

Проблематично, насколько верно расставлены тактовые черты, поскольку в некоторых тактах содержится по три семибревиса, в других же, в том же мадригале, 4/4. Есть даже предположение, что это сделано не издателем Молинаро, а печатником Павони.

Последнее издание сочинений Джезуальдо в ту эпоху относится к 1626 г., после чего оно возобновилось только в 1957 г. Издание Вайсмана и Уоткинса сделано по Молинаро (Nach dem Partiturdruck von 1613). Парадоксально, но в Италии до сих пор нет издания сочинений Джезуальдо. В связи с 400-летием со дня смерти Джезуальдо, которое отмечалось в Италии в 2013 году [См.: 2], 
в числе многочисленных мероприятий обсуждался и вопрос издания полного собра- ния сочинений Джезуальдо. Интересно увидеть, как оно будет оформлено.

\section{ЛИТЕРАТУРА}

1. Григорьева М.А. Иконография Джезуальдо: вымысел и правда // Ученые записки Российской академии музыки им. Гнесиных. 2012. № 1. С. 30-36.

2. Григорьева М.А. Год Джезуальдо в Италии (путевые заметки) // Музыка и время. 2014. № 11. C. $37-41$.

3. Gaspari on line [электронный ресурс] Режим доступа: http://www.bibliotecamusica.it/cmbm/ scripts/gaspari/src_aut.as $\rho$

4. Modestino C. Della dimora di Torquato Tasso in Napoli negli anni 1588, 1592, 1594: discorsi tre di Carmine Modestino. Napoli: stab. tip. di G. Cataneo, 1863. 306 p.

5. Newcomb A. Carlo Gesualdo and a Musical Correspondence of 1594 // The Musical Quarterly. 1968. Vol. 54. №. 4. P. 409-436.

6. Stanco G. Carlo Gesualdo: La vita e il destino come dramma in musica // All'ombra principesca. Atti del convegno di studi «Carlo Gesualdo nella storia d'Irpinia, della musica e delle arti». Lucca: Libreria musicale italiana, 2006. P. 87-148.

7. Vaccaro A. Carlo Gesualdo, principe di Venosa: l'uomo e i tempi. Venosa: Edizioni Osanna, 1998. $216 \rho$.

8. Watkins G. Gesualdo: The Man and his music. London: Oxford University Press, 1973. 334 o.

9. Watkins G. The Gesualdo Hex: Music, Myth, and Memori. NY: Norton \& Company Inc, 2010. $384 \rho$.

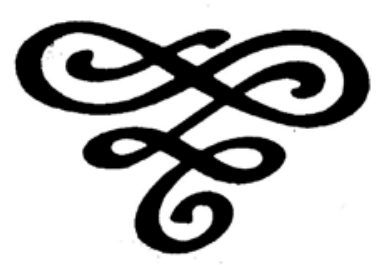

